\title{
Effects of muscle fatigue on ankle and the fatigue protocols of postural control
}

\author{
YH Shin, $\mathrm{CH}$ Youm*, YK Kim \\ From 4th Congress of the International Foot and Ankle Biomechanics (i-FAB) Community \\ Busan, Korea. 8-11 April 2014
}

Postural control is composed of the integration of vision, vestibular system, and proprioceptive sense along with the balanced control of the musculoskeletal system $[1,2]$. Muscle fatigue can be defined as the decrease in the maximum muscular strength production capacity due to high intensity or prolonged exercise during physical activity $[3,4]$. Most studies related to muscle fatigue and postural control use isokinetic dynamometers. Angular speed has mostly been used, being divided into slow $[5,6]$ and fast angular speeds $[7,8]$. The fast angular speed is mainly used for low intensity, long-duration exercise and the slow angular speed is used for high intensity, shortduration exercise $[9,10]$. Hence, an understanding of the change in postural control capabilities according to fatigue induction properties of various movements such as plantar flexion and dorsiflexion is deemed necessary.

The purpose of this study was to investigate the effects of muscle fatigue on ankle joint and the fatigue protocols of postural control during single-leg stance. The subjects of this study were 24 healthy adult women. Fatigue was induced on plantar flexion and dorsiflexion with an isokinetic dynamometer at angular velocities of $30 \%$ and $120 \%$ s.

Among the anteroposterior plane factors, plantar and dorsiflexion resulted in decreased postural control during single-leg stance after fatigue induction using a plantar and dorsiflexion fatigue protocol at an angular velocity of $30 \%$. No change was observed in the postural control during single-leg stance postural control on application of the fatigue protocol at an angular velocity of $120 \%$ s. Plantar and dorsiflexion did not differ significantly with the application of the fatigue protocol at angular velocities of $30 \%$ and $120 \%$ s. Among the mediolateral plane factors, postural control diminished during single-leg stance after fatigue induction on application of the plantar and dorsiflexion fatigue protocol at an angular velocity of $30 \%$. On application of the fatigue protocol an angular velocity of $120 \%$ s, however, no change in the postural control was observed during single-leg stance. Thus, the plantar and dorsiflexion fatigue protocol applied at an angular velocity of $30 \%$ resulted in decreased single-leg stance postural control compared to that observed at an angular velocity of $120 \%$.

In summary, during high-intensity, short-duration exercise involving plantar and dorsiflexion at an angular velocity of $30 \%$, fatigue at $50 \%$ of the maximum plantar flexion torque might result in reduced single-leg stance postural control.

Published: 8 April 2014

\section{References}

1. Boyas S, Remaud A, Bisson EJ, Cadieux S, Morel B, Bilodeau M: Impairment in postural control is greater when ankle plantarflexors and dorsiflexors are fatigued simultaneously than when fatigued separately. Gait \& Posture 2011, 34(2):254-259.

2. Shumway-Cook A, Woollacott MH: Motor control. Theory and practical applications. 2 edition. Baltimore, Williams \& Wilkins; 2000, 163-191.

3. Allen DG, Westerblad $\mathrm{H}$ : Role of phosphate and calcium stores in muscle fatigue. Journal of physiology 2001, 536:657-665.

4. Lorist MM, Kernell D, Meijman TF, Zijdewind I: Motor fatigue and cognitive task performance in humans. Journal of Physiology 2002, 545:313-319.

5. Gribble PA, Hertel J: Effect of hip and ankle muscle fatigue on unipedal postural control. Journal of Electromyography and Kinesiology 2004a, 14:641-646.

6. Gribble PA, Hertel J: Effect of lower-extremity muscle fatigue on postural control. Archives of Physical Medicine and Rehabilitation 2004b, 85(4):589-592.

7. Yaggie JA, McGregor SJ: Effects of isokinetic ankle fatigue on the maintenance of balance and postural limits. Archives of physical Medicine and Rehabilitation 2002, 83(2):224-228.

8. Bellew JW, Fenter PC: Control of balance differs after knee or ankle fatigue in older women. Archives of Physical Medicine and Rehabilitation 2006, 87:1486-1489.

9. Salavati M, Moghadam M, Ebrahimi I, Arab AM: Changes in postural stability with fatigue of lower extremity frontal and sagittal plane movers. Gait \& Posture 2007, 26:214-218.

\footnotetext{
* Correspondence: chyoum@dau.ac.kr

Sport Biomechanics Laboratory, University of Dong-A, Busan, Korea
} 
10. Gerodimos V, Mandou V, Zafeiridis A, Loakimidis P, Stavropoulos N, Kellis S: Isokinetic peak torque and hamstring/quadriceps ratios in young basketball players. effects of age, velocity, and contraction mode. The Journal of Sports Medicine and Physical Fitness 2003, 43:444-452.

doi:10.1186/1757-1146-7-S1-A111

Cite this article as: Shin et al:: Effects of muscle fatigue on ankle and the fatigue protocols of postural control. Journal of Foot and Ankle Research 2014 7(Suppl 1):A111.

Submit your next manuscript to BioMed Central and take full advantage of:

- Convenient online submission

- Thorough peer review

- No space constraints or color figure charges

- Immediate publication on acceptance

- Inclusion in PubMed, CAS, Scopus and Google Scholar

- Research which is freely available for redistribution

Submit your manuscript at www.biomedcentral.com/submit
C Biomed Central 